\title{
Rice grain resistance to brown spot and yield are increased by silicon
}

\author{
Leandro J. Dallagnol ${ }^{1}$, Fabricio A. Rodrigues ${ }^{2}$, Mateus V. B. Mielli² \& Jian F. Ma $^{3}$
}

${ }^{1}$ Departamento de Fitossanidade, Laboratório Interação Planta-Patógeno, Universidade Federal de Pelotas, 96010-900, Pelotas, RS, Brazil; ${ }^{2}$ Departamento de Fitopatologia, Laboratório de Interação Patógeno-Hospedeiro, Universidade Federal de Viçosa, 36570-900, Viçosa, MG, Brazil; ${ }^{3}$ Research Institute for Bioresources, Okayama University, Chuo 2-20-1, Kurashiki 720-0046, Japan

Author for correspondence: Fabrício A. Rodrigues, e-mail: fabricio@ufv.br

\begin{abstract}
Brown spot, caused by Bipolaris oryzae, is one of the most important diseases of rice and can cause a reduction in yield and grain quality. The effect of silicon (Si) on the resistance of rice grains to brown spot was investigated. Plants from cv. Oochikara and its mutant, defective in the Lsil transporter (lsil mutant), were grown in hydroponic culture either with $\mathrm{Si}(+\mathrm{Si} ; 2 \mathrm{mM})$ or without $\mathrm{Si}(-\mathrm{Si})$. Panicle inoculation with $B$. oryzae was carried out at the beginning of the milk-grain stage. Panicles were harvested at physiological grain maturity. The supply of Si significantly increased Si concentration in husks compared to -Si plants. Si concentration in husks from cv. Oochikara was up to three times greater than the $l s i 1$ mutant. In the presence of Si, brown spot severity was reduced by $88 \%$ in grains from cv. Oochikara and by $53 \%$ in grains from $l s i 1$ mutant. Brown spot severity was $77 \%$ lower for grains of cv. Oochikara than for the $l s i 1$ mutant, both plant types were grown in the presence of Si. Panicle inoculation reduced significantly the following yield components: number of grains per panicle, the weight of 1000 grains and the percentage of filled grains. Si significantly increased these yield components, especially for inoculated panicles. Considering kernel quality, the panicle inoculation with B. oryzae significantly reduced the yield of husked kernel, yield of whole kernel and kernel diameter, especially for grains from -Si plants. For panicles from + Si plants, the kernel quality was improved under inoculation, compared to -Si plants. Results from this study show that Si improved rice yield and kernel quality in panicles inoculated with $B$. oryzae. Furthermore the functional Lsil gene contributed significantly for increasing the yield of whole kernel and kernel diameter, possibly due to the increasing Si concentration in husks.
\end{abstract}

Key words: Bipolaris oryzae, Oryza sativa, kernel quality, Lsil gene, rice yield.

\section{INTRODUCTION}

Rice (Oryza sativa L.) is the main source of food for approximately half of the world's population (Maclean et al., 2002). For rice consumers, whole grains free from defects are preferred and this factor determines the price that growers will receive (Soave et al., 1984). Grain quality is affected by several abiotic and biotic factors $(\mathrm{Ou}$, 1985). The biotic damage is related to fungal and bacterial incidence and injuries caused by insects (Marchetti et al., 1984). The fungus Bipolaris oryzae (Breda de Haan) Shoemaker, the causal agent of brown spot of rice, reduces yield and negatively impacts grain quality (Ou, 1985).

Leaf infection by $B$. oryzae did not significantly affect panicle number per plant or the number of spikelets per panicle, but caused a decline in yield by increasing the number of empty grains, reducing the number of grains per panicle and grain weight (Aluko, 1975; Prabhu et al., 1980). While the relation between $B$. oryzae infection on leaf and grain is controversial (Marchetti et al., 1984; Ba \& Sangchote, 2006), the negative impact of grain infection causing discoloration and reduction in milling quality is well documented (Marchetti et al., 1984; Soave et al., 1984). In Brazil, B. oryzae is one of the most common rice grain pathogens (Soave et al., 1984), which can infect the husks and even the inside area of the kernel (Ou, 1985). Brown spot symptoms are more commonly observed on leaves and glumes (grain husks), but sometimes may also appear on the coleoptiles, sheaths and panicle branches (Ou, 1985). The characteristic symptoms of brown spot on leaves and glumes include light reddish-brown lesions or lesions with a gray center surrounded by a dark to reddish-brown margin and then by a bright yellow halo (Dallagnol et al., 2009).

Currently, the major management strategies available for brown spot include the use of rice cultivars partially resistant, appropriate plant nutrition and fungicide application (Reunião Técnica da Cultura do Arroz Irrigado, 2012). Previously, the addition of silicon ( $\mathrm{Si}$ ) to the soil has been reported to provide a viable alternative to reduce brown spot severity (Nanda \& Gangopadhyay, 1984; Datnoff et al., 1991; 1992; 1997; 2007; Dallagnol et al., 2009). The addition of Si to rice plants has also reduced other important diseases, such as blast, grain discoloration, leaf blight, leaf 
scald, sheath blight and stem rot (Korndörfer et al., 1999; Datnoff et al., 2007). Seebold et al. (2000) reported that applying $1000 \mathrm{~kg} \mathrm{ha}^{-1}$ of Si increased rice yield up to $42 \%$ and reduced grain discoloration up to $70 \%$.

Rice accumulates $\mathrm{Si}$ in the shoots in concentrations several times greater than macronutrients such as nitrogen, phosphorus and potassium (Datnoff et al., 2007). Rice requires large concentrations of Si readily available in the root zone for vigorous growth and high yield (Ma et al., 2002). The high Si accumulation in rice shoots is caused by an active uptake system that utilizes the proteins involved in $\mathrm{Si}$ influx from the soil solution to the cytoplasm of the root cells (Lsi1), efflux from the cell cytoplasm to the xylem (Lsi2) and the subsequent distribution of $\mathrm{Si}$ in the rice shoots (Lsi 6) (Ma et al., 2008; Yamaji et al., 2009). Mutation in the Lsil gene of cv. Oochikara resulted in a mutant plant named low silicon rice 1 (lsil) that uptakes Si only through passive transport (Ma et al., 2002). Plant with the lsil mutation, in addition to expressing a significant reduction in yield under field conditions (Ma et al., 2002), also have the defense against brown spot development on the leaves compromised, suggesting that a minimum $\mathrm{Si}$ concentration is necessary to achieve an acceptable level of resistance against this disease (Dallagnol et al., 2009; 2011). Ma et al. (2006) reported that the Si uptake by the lsil mutant was significantly reduced compared to that of wild plants, resulting in grain production of one-tenth of that of wild-type rice and with a higher disease severity on the husks.

This study aimed to demonstrate the contribution of the Lsil gene to increase rice grain resistance to brown spot and for improving yield and kernel quality under greenhouse conditions.

\section{MATERIALS AND METHODS}

\section{Nutrient solution preparation}

The nutrient solution used for the hydroponic growth of rice plants was prepared based on Hoagland \& Arnold (1950) with some modifications, and included the following macronutrients: $1 \mathrm{mM} \mathrm{KNO}_{3}, 0.25 \mathrm{mM} \mathrm{NH}_{4} \mathrm{H}_{2} \mathrm{PO}_{4}, 0.1 \mathrm{mM}$ $\mathrm{NH}_{4} \mathrm{Cl}, 0.5 \mathrm{mM} \mathrm{MgSO}{ }_{4} \cdot 7 \mathrm{H}_{2} \mathrm{O}$ and $1 \mathrm{mM} \mathrm{Ca}\left(\mathrm{NO}_{3}\right) \cdot 4 \mathrm{H}_{2} \mathrm{O}$; and the following micronutrients: $0.3 \mu \mathrm{M} \mathrm{CuSO}_{4} .5 \mathrm{H}_{2} \mathrm{O}, 0.3$ $\mu \mathrm{M} \mathrm{ZnSO}{ }_{4} \cdot 7 \mathrm{H}_{2} \mathrm{O}, 11.5 \mu \mathrm{M} \mathrm{H}_{3} \mathrm{BO}_{3}, 3.5 \mu \mathrm{M} \mathrm{MnCl}_{2} .4 \mathrm{H}_{2} \mathrm{O}$, $0.1 \mu \mathrm{M}\left(\mathrm{NH}_{4}\right)_{6} \mathrm{Mo}_{7} \mathrm{O}_{24} \cdot 4 \mathrm{H}_{2} \mathrm{O}, 25 \mu \mathrm{M} \mathrm{FeSO} \cdot 7 \mathrm{H}_{2} \mathrm{O}$ and 25 $\mu \mathrm{M}$ Bisodic EDTA. Si was supplied to the plants in the form of silicic acid, prepared by passing potassium silicate through a cation-exchange resin (Amberlite IR-120B, $\mathrm{H}^{+}$ form) (Sigma-Aldrich). The Si rates used were 0 or $2 \mathrm{mM}$. The $\mathrm{pH}$ of the nutrient solution was 5.5 and was not affected by the addition of the silicic acid.

\section{Plant growth}

Rice seeds from cv. Oochikara and the lsil mutant were surface sterilized in $10 \%(\mathrm{v} / \mathrm{v}) \mathrm{NaOCl}$ for $1.5 \mathrm{~min}$, rinsed in sterilized water for $3 \mathrm{~min}$, and germinated on distilled-water-soaked germitest paper (Fisher Scientific) in a germination chamber (MA-835/2106UR, Marconi) at $25^{\circ} \mathrm{C}$ and $12 \mathrm{~h}$ photoperiod $\left(\approx 125 \mu \mathrm{mol}\right.$ photons $\left.\mathrm{m}^{-2} \mathrm{~s}^{-1}\right)$ for six days. The germinated seedlings were transferred to plastic pots $(0.5 \mathrm{~L})$ and were amended with a one-half strength nutrient solution without $\mathrm{Si}$. After two days, the young seedlings were transferred to new plastic pots (30$\mathrm{cm}$ diameter) containing $5 \mathrm{~L}$ of nutrient solution with or without Si. Six rice plants were grown in each pot. Every four days, the non-aerated nutrient solution was changed for new solution either with or without $\mathrm{Si}$. The electrical conductivity and the $\mathrm{pH}$ of the nutrient solution were checked daily. The $\mathrm{pH}$ was maintained at approximately 5.5 using $\mathrm{NaOH}$ or $\mathrm{HCl}(1 \mathrm{M})$ as needed. The plants were grown in a greenhouse (relative humidity of $60 \pm 5 \%$, temperature of $30 \pm 5^{\circ} \mathrm{C}$ ) during the experiments. The relative humidity and temperature were measured using a thermo-hygrograph (TH-508, Impac). The photon flux density on sunny days inside the greenhouse (at midday), quantified with a $\mathrm{Li} 250 \mathrm{~A}$ light meter (Li-Cor Environmental), was approximately 900 $\mu \mathrm{mol}$ photons $\mathrm{m}^{-2} \mathrm{~s}^{-1}$.

\section{Inoculation procedure}

An isolate of B. oryzae (CNPAF-HO 82; Embrapa Arroz e Feijão, Santo Antônio de Goiás, GO, Brazil) obtained from symptomatic rice plants was preserved on pieces of filter paper in glass vials with silica gel at $4^{\circ} \mathrm{C}$. Pieces of filter paper containing the fungus were transferred to Petri dishes containing potato-dextrose-agar (PDA). After three days, PDA plugs $\left(0.5 \mathrm{~cm}^{2}\right)$ containing fungal mycelia were transferred to new Petri dishes. Petri dishes were maintained in a growth chamber at $25^{\circ} \mathrm{C}$ with a $12 \mathrm{~h}$ photoperiod for 10 days. To obtain conidial suspension, $10 \mathrm{~mL}$ of sterilized water was added to Petri dishes containing fungal conidia, mixed using a Drigalski handle and then filtered through cotton gauze to remove mycelia. The suspension was adjusted to $5 \times 10^{3}$ conidia $\mathrm{mL}^{-1}$ using a hemocytometer and was applied as a fine mist to the panicles of each plant at the beginning of the milk-grain stage (IRRI, 1996) until runoff using a VL Airbrush atomizer (Paasche Airbrush Co.). Gelatin $(1 \%, \mathrm{w} / \mathrm{v})$ was added to the sterile water before inoculum preparation to aid conidial adhesion to the panicles. Only the panicles were inoculated with $B$. oryzae, while the leaves were protected with plastic during application of the conidial suspension. Immediately after inoculation, the plants were transferred to a mist chamber maintained at $25 \pm 2^{\circ} \mathrm{C}$ and $85 \pm 5 \%$ relative humidity, measured as described above. The plants with inoculated and noninoculated panicles were exposed to an initial $24 \mathrm{~h}$ dark period, followed by $48 \mathrm{~h}$ of $12 \mathrm{~h}$ photoperiods $(\approx 15 \mu \mathrm{mol}$ photons $\mathrm{m}^{-2} \mathrm{~s}^{-1}$ ) provided by cool-white fluorescent lamps. The plants with non-inoculated and inoculated panicles were kept in separate mist chambers but were exposed to the same conditions. After $72 \mathrm{~h}$, the plants were transferred to a greenhouse with the environmental conditions described above for the duration of the experiment. 


\section{Experimental design}

Two $2 \times 2 \times 2$ factorial experiments, consisting of the two $\mathrm{Si}$ rates $(0$ or $2 \mathrm{mM}$, referred to as $-\mathrm{Si}$ and $+\mathrm{Si}$ treatments, respectively), the plant types (cv. Oochikara and lsil mutant), and the non-inoculated and inoculated panicles from both plant type, were arranged in a completely randomized design with three replications. Each experimental unit consisted of one plastic pot containing six rice plants. A total of 18 plants were used for each treatment and the number of panicles per plant ranged from four to six. The experiment was carried out twice.

\section{Evaluations}

At the stage of physiological maturity (IRRI, 1996), 40 days after inoculation, all inoculated and non-inoculated panicles were hand-harvested. At least 30 panicles for each replication of each treatment were used for the evaluations. Grains from the panicles of each plant were used to evaluate the severity of brown spot on grains, yield components, grain quality and the Si concentration in the husks.

\section{Disease evaluation and calculation of brown spot index (BSI)}

Brown spot severity on the grains of each panicle per plant was scored using a 0-7 scale, modified from IRRI (1996) as follows: $0=$ no disease symptoms, $1=$ less than $1 \%, 2=$ from 1.1 to $5 \%, 3=$ from 5.1 to $10 \%, 4=$ from 10.1 to $25 \%, 5=$ from 25.1 to $50 \%, 6=50.1$ to $75 \%$, and $7=$ more than $75 \%$ of the grains' surface with disease symptoms. Data for brown spot severity were used to calculate the BSI based on the formula proposed by McKinney (1923) where: BSI $=[\Sigma($ rate of the disease scale $\times$ number of grains receiving that rate)/(total number of grains $\times$ the highest rate of the disease scale) $] \times 100$.

\section{Yield components}

On each panicle, the total number of grains and the percentage of filled grains were determined. A grain was considered filled only if the endosperm was present. The filled and non-filled grains from all the plants in each replicate were used to determine the weight of 1000 grains of rice. To standardize nomenclature, the term grain was used for paddy rice and kernel for grains without husks.

\section{Kernel quality measurements}

Kernel quality was determined after stripping and burnishing the kernel (Houston, 1972). For the purpose of stripping, samples of $100 \mathrm{~g}$ of grain were processed in a mill for $1 \mathrm{~min}$. Next, the kernel were polished and weighed. The weight values of husked kernel (broken and whole kernel) were considered to be the yield of husked kernel (YHK). Subsequently, the polished kernel were placed in a separator and processed for $30 \mathrm{sec}$ in order to separate broken kernel from whole kernel. The remaining kernels in the sieve were weighed to obtain the weight of whole kernel, expressed in percentage as yield of whole kernel (YWK). Samples $(\approx 100$ kernels) of the whole kernel were used to obtain kernel diameter (in $\mathrm{mm}$ ) using a digital caliper.

\section{Concentration of Si in husks}

The grain husks were collected at the end of the stripping process, dried at $65^{\circ} \mathrm{C}$ for $72 \mathrm{~h}$ and ground with a Thomas-Wiley mill (Thomas Scientific) to pass through a 40 -mesh screen. The $\mathrm{Si}$ concentration in the husks was determined by a colorimetric analysis on $0.1 \mathrm{~g}$ of dried and alkali-digested tissue (Korndörfer et al., 2004).

\section{Data analysis}

Cochran's test for homogeneity of variance indicated that the data from the two experiments could be pooled, so the data were pooled for analysis as a single six replications experiment. The experiment-treatment interactions were not significant $(P \geq 0.05)$ when compared to the treatments main effects. The data were analyzed by an analysis of variance (ANOVA), significant interactions were sliced and the treatment mean comparisons were analyzed by F-test using SAS version 8.0 (SAS Institute).

\section{RESULTS}

\section{Concentration of $\mathrm{Si}$ in husks}

The factors Si rate and plant type as well as the interaction Si rate $\times$ plant type were significant (Table 1). Si concentration was significantly greater by 460 and $175 \%$, respectively, for the husks of grains from cv. Oochikara and the $l s i 1$ mutant plants supplied with $\mathrm{Si}$ as compared to husks of grains from -Si plants (Table 2). Husks from grains of cv. Oochikara contained significantly greater $(238 \%$ for $+\mathrm{Si}$ plants and $66 \%$ for -Si plants) Si concentration as compared to the lsil mutant.

\section{Brown spot index (BSI)}

For the BSI index, the factor Si rate, plant type and the interaction Si rate $\times$ plant type were significant (data not showed). In the presence of $\mathrm{Si}$, the BSI was significantly reduced by $88 \%$ and $53 \%$, respectively, for the cv. Oochikara and lsi 1 mutant grain compared with the -Si treatment (Table 2). For the cv. Oochikara, the BSI was significantly reduced by $77 \%$ and $15 \%$ for $+\mathrm{Si}$ and $-\mathrm{Si}$ treatment, respectively, compared to the lsil mutant.

\section{Yield components}

The factors Si rate and panicle inoculation were significant for the number of grains per panicle, weight of 1000 grains, and percentage of filled grain (Table 1). The interaction of Si rate and panicle inoculation was significant for the percentage of filled grain (Table 1). Si supply significantly increased by $22 \%$ and $12 \%$, respectively, the number of grains per panicle and the weight of 1000 grains, compared to -Si plants (Table 3). On panicles inoculated with B. oryzae, the number of grains per panicle and the weight of 1000 grains were significantly reduced by $6.5 \%$ and $19 \%$, 
TABLE 1 - Analysis of variance for the effects of silicon rates (Sir), plant types (PT), and panicle inoculation (PI) on silicon (Si) concentration in the husks, number of grains per panicle (NGP), weight of 1000 grains (1000GW), filled grains (FG), yield of husked kernel (YHK), yield of whole kernel (YWK) and kernel diameter (KD).

\begin{tabular}{|c|c|c|c|c|c|c|c|c|}
\hline \multirow[t]{2}{*}{ Source of variation } & \multicolumn{8}{|c|}{$F$ values } \\
\hline & d.f. & Si & NGP & $1000 \mathrm{GW}$ & FG & YHK & YWK & KD \\
\hline Sir & 1 & $2,241.49^{*}$ & $180.13^{*}$ & $12.79^{*}$ & $51.59^{*}$ & $4.85^{*}$ & $47.28^{*}$ & $134.39^{*}$ \\
\hline PT & 1 & $1,318.49^{*}$ & 2.38 & 1.01 & 0.82 & 1.07 & $11.48^{*}$ & $9.00^{*}$ \\
\hline PI & 1 & 0.20 & $12.11^{*}$ & $43.90^{*}$ & $63.07^{*}$ & $14.00^{*}$ & $91.22^{*}$ & $50.78^{*}$ \\
\hline $\mathrm{PT} \times \mathrm{PI}$ & 1 & 0.23 & 0.02 & 0.04 & 1.27 & 0.09 & 0.50 & 0.69 \\
\hline Sir $\times$ PI & 1 & 3.20 & 0.06 & 0.40 & $16.96^{*}$ & 0.77 & $7.63^{*}$ & $46.04^{*}$ \\
\hline $\mathrm{PT} \times \mathrm{Sir}$ & 1 & $884.45^{*}$ & 0.65 & 0.00 & 0.71 & 0.01 & $14.58^{*}$ & $17.56^{*}$ \\
\hline $\mathrm{PT} \times \operatorname{Sir} \times \mathrm{PI}$ & 1 & 1.18 & 0.05 & 0.87 & 0.61 & 0.09 & 1.02 & 2.03 \\
\hline Error & 40 & - & - & - & - & - & - & - \\
\hline
\end{tabular}

${ }^{*}=$ significant at $p<0.05$.

TABLE 2 - Silicon concentration ( $\mathrm{Si}$ ) and brown spot index (BSI) in the husk of rice grains from plants of cultivar Oochikara and $l s i 1$ mutant grown in hydroponic culture amended with $0(-\mathrm{Si})$ or $2(+\mathrm{Si}) \mathrm{mM}$ of silicon and subjected or not to panicle inoculation with Bipolaris oryzae.

\begin{tabular}{|c|c|c|c|c|c|c|}
\hline \multirow[t]{2}{*}{ Plant type } & \multicolumn{3}{|c|}{$\mathrm{Si}\left(\mathrm{g} \mathrm{kg}^{-1}\right)$} & \multicolumn{3}{|c|}{ BSI } \\
\hline & $-\mathrm{Si}$ & $+\mathbf{S i}$ & $P$ & $-\mathrm{Si}$ & $+\mathrm{Si}$ & $P$ \\
\hline Oochikara & 5.3 & 29.7 & $<0.05$ & 65.5 & 8.1 & $<0.05$ \\
\hline lsil mutant & 3.2 & 8.8 & $<0.05$ & 77.0 & 35.6 & $<0.05$ \\
\hline$P$ & $<0.05$ & $<0.05$ & & $<0.05$ & $<0.05$ & \\
\hline
\end{tabular}

The factor interaction effects were sliced and means compared by $F$-test. Data showed are from two pooled experiments.

respectively, compared to non-inoculated panicles (Table $3)$. The percentage of filled grains was significantly reduced by $28 \%$ and $8 \%$, respectively, for inoculated panicles from $-\mathrm{Si}$ and $+\mathrm{Si}$ plants, compared to non-inoculated panicles (Table 4). The percentage of filled grains was significantly higher by $37 \%$ and $7 \%$, respectively, for inoculated and noninoculated panicles from $+\mathrm{Si}$ plants compared to panicles from -Si plants (Table 4).

\section{Kernel quality measurements}

The factors Si rate and panicles inoculation were significant for the yield of husked kernel (Table 1). For the yield of whole kernel and kernel diameter, the factors Si rate, plant type, and panicle inoculation and the interactions Si rate $\times$ plant type and Si rate $\times$ panicle inoculation were significant (Table 1). Yield of husked kernel increased significantly by $6 \%$ for + Si plants as compared to -Si plants (Table 5). Panicle inoculation reduced significantly by $7 \%$ the yield of husked kernel compared to non-inoculated panicles (Table 5). Yield of whole kernel significantly increased by $11 \%$ and $6 \%$ for cv. Oochikara and $l s i 1$ mutant plants supplied with $\mathrm{Si}$ as compared to -Si plants (Table 6). The yield of whole kernel for $+\mathrm{Si} \mathrm{cv}$. Oochikara was $8 \%$ higher than for $+\mathrm{Si} l s i 1$ mutant, while there were not significant differences between plant types in the absence of Si. Panicle inoculation reduced by $10 \%$ and $9 \%$, respectively, the yield of whole kernel for -Si and +Si plants compared to non-inoculated panicles (Table 6). Si supplied to rice plants increased the yield of whole kernel by 8 and 7\%, respectively, for inoculated and non-inoculated panicles compared to -Si plants (Table 6). Kernel diameter significantly increased by 7 and $11 \%$ for cv. Oochikara and lsil mutant plants supplied with $\mathrm{Si}$ as compared to kernel from -Si plants (Table 7). Considering plant type, $-\mathrm{Si}$ cv. Oochikara produced kernel $6 \%$ larger in diameter compared to -Si lsil mutant. On the other hand, there was no significant difference between plant types in the presence of $\mathrm{Si}$ (Table 7). Kernel diameter significantly increased by $15 \%$ and $4 \%$, respectively, for $+\mathrm{Si}$ inoculated and $+\mathrm{Si}$ non-inoculated plants compared to kernel from -Si plants (Table 7). Panicle inoculation significantly reduced the kernel diameter by $10 \%$ for $-\mathrm{Si}$ plants compared to panicles from non-inoculated plants (Table 7). On the other hand, for the + Si plants there was no significant effect of panicle inoculation on the kernel diameter.

\section{DISCUSSION}

This study reports the influence of Si on the increase of rice grain resistance to brown spot and the beneficial effect of this element on rice yield and kernel quality. Additionally, this study reports that the functional Lsil gene favored an increase in Si concentration in the husks. The impairment in the Si transporter for $l s i l$ mutant reduced the Si concentration in the husks up to three times compared with the cv. Oochikara (Table 2), even when this element was available for plant uptake. According to Tamai \& Ma (2008), the rice $l s i 1$ mutant was only affected in Si uptake capacity and the mutation on the Lsil gene was related to 
TABLE 3 - Number of grains per panicle (NGP) and 1000 grains weight $(1000 \mathrm{GW})$, for rice grains from plants of cultivar Oochikara and lsil mutant grown in hydroponic culture amended with $0(-\mathrm{Si})$ or $2(+\mathrm{Si}) \mathrm{mM}$ of silicon and subjected or not to panicle inoculation with Bipolaris oryzae.

\begin{tabular}{lrc}
\hline \hline Si rates & NGP & 1000 GW (g) \\
$-\mathrm{Si}$ & 76.5 & 32.7 \\
$+\mathrm{Si}$ & 93.7 & 36.5 \\
$P$ & $<0.05$ & $<0.05$ \\
\hline Panicle inoculation & & \\
Inoculated & 80.1 & 31.1 \\
Non-inoculated & 85.7 & 38.1 \\
$P$ & $<0.05$ & $<0.05$ \\
\hline
\end{tabular}

The factor interaction effects were sliced and means compared by $F$-test. Data showed are from two pooled experiments.

TABLE 4 - Percentage of filled grains (FG) in rice panicles from plants of cultivar Oochikara and $l s i 1$ mutant grown in hydroponic culture amended with $0(-\mathrm{Si})$ or $2(+\mathrm{Si}) \mathrm{mM}$ of silicon and subjected or not to panicle inoculation with Bipolaris oryzae.

\begin{tabular}{lccc}
\hline Si rates & \multicolumn{3}{c}{ FG (\%) } \\
\cline { 2 - 4 } & Inoculated & Non-inoculated & $\boldsymbol{P}$ \\
\hline$-\mathrm{Si}$ & 53.4 & 74.5 & $<0.05$ \\
$+\mathrm{Si}$ & 73.1 & 79.8 & $<0.05$ \\
$P$ & $<0.05$ & $<0.05$ & \\
\hline
\end{tabular}

The factor interaction effects were sliced and means compared by $F$-test. Data showed are from two pooled experiments.

TABLE 5 - Yield of husked kernel (YHK) for rice grains from plants of cultivar Oochikara and lsil mutant grown in hydroponic culture amended with $0(-\mathrm{Si})$ or $2(+\mathrm{Si}) \mathrm{mM}$ of silicon and subjected or not to panicle inoculation with Bipolaris oryzae.

\begin{tabular}{lc}
\hline \hline Si rates & YHK $(\%)$ \\
$-\mathrm{Si}$ & 73.6 \\
$+\mathrm{Si}$ & 77.8 \\
$P$ & $<0.05$ \\
\hline Panicle inoculation & \\
Inoculated & 73.5 \\
Non-inoculated & 79.0 \\
$P$ & $<0.05$ \\
\hline
\end{tabular}

The factor interaction effects were sliced and means compared by $F$-test. Data showed are from two pooled experiments.

reduction in the grain yield under field conditions. Results from the present study indicated that the reduction of $\mathrm{Si}$ concentration in the husks of grains from the lsil mutant reduced grain's resistance to brown spot and also the yield of whole kernel from inoculated panicles (Tables 2 and 6).

The importance of the Lsil gene in increasing brown spot resistance in the grains by Si uptake was indicated by the greater reduction in BSI for grains from cv. Oochikara with Si than that found for the lsil mutant. Although not determinate in this study, the reduction on the BSI may be associated to the state of priming (anticipation and increase in plant defense under pathogen attack) caused by the presence of soluble $\mathrm{Si}$ in the plant tissue as previously proposed (Gareeb et al., 2011; Dallagnol et al., 2012; Van Bockhaven et al., 2012). The earlier activation of plant defenses by $\mathrm{Si}$ against $B$. oryzae infection on rice leaves was previously reported by Dallagnol et al. (2011) and involved higher activity of chitinases and peroxidases, greater concentration of phenolic compounds and lignin, lower lipid peroxidation and less electrolyte leakage. Additionally to priming plant defenses, the higher concentration of Si beneath the cuticle may avoid or delay the delivery of pathogenicity and aggressiveness factors into the plant cell by the pathogens as pointed out by Bélanger et al. (2012), thus contributing to the reduction on host tissue colonization by the pathogen and could also explain the lower BSI on plants from cv. Oochikara supplied with $\mathrm{Si}$.

The lower BSI in the glumes of the plants supplied with $\mathrm{Si}$, mainly for the cv. Oochikara, compared with the plants without Si resulted in a higher yield and better kernel quality after milling (Tables 3, 6 and 7). Even though no significant differences were found between cv. Oochikara and lsil mutant for the majority of the grain variables evaluated, regardless of Si supply, in a previous study Tamai \& Ma (2008) reported that under field conditions where the plants were exposed to typhoons and the occurrence of disease on leaves, plants of lsil mutant showed significant reduction in the number of grains and in the percentage of filled grains. The absence of differences between plant types for the grain yield components in the present study may be associated to the less stressful environment under greenhouse in which only pathogen inoculation on panicles was the stress that the plants were exposed. Furthermore, no disease symptoms were observed on leaves because they were protected during panicle inoculation. According to Tamai \& Ma (2008), the beneficial effects of Si might have been underestimated under greenhouse conditions due to a less stressful environment as compared to experiments carried out under field conditions.

Although no significant differences were found between the lsil mutant and cv. Oochikara for the number of grains per panicle, the weight of 1000 grains and the percentage of filled grains, both plant types supplied with $\mathrm{Si}$ showed an increase in these yield components (Tables 3, 4, 5, 6 and 7). This indicates that increasing Si concentration in the shoots and husks may improve rice yield when plants are grown in a stress-free environment. On the other hand, the number of grains per panicle was negatively affected on panicles inoculated with $B$. oryzae regardless of plant types (Table 3). This result indicates that infection by $B$. oryzae during milk-grain stage can reduce the number of grains per panicle, contradicting the previous studies that also reported reduction in the number of grains per panicle due to $B$. oryzae infection during panicle development, but only when infection occurred before the grain-filling stage (Aluko, 1975; Prabhu et al., 1980). However, Si supplied to 
Rice grain resistance to brown spot and yield are increased by silicon

TABLE 6 - Yield of whole kernel (YWK) of rice grains from plants of cultivar Oochikara and lsil mutant grown in hydroponic culture amended with $0(-\mathrm{Si})$ or $2(+\mathrm{Si}) \mathrm{mM}$ of silicon and subjected or not to panicle inoculation with Bipolaris oryzae.

\begin{tabular}{|c|c|c|c|c|c|c|}
\hline \multirow[t]{2}{*}{ Si rates } & \multicolumn{3}{|c|}{ YWK (\%) } & \multicolumn{3}{|c|}{ YWK (\%) } \\
\hline & Oochikara & lsil mutant & $P$ & Inoculated & Non-inoculated & $P$ \\
\hline$-\mathrm{Si}$ & 55.1 & 53.9 & 0.623 & 52.0 & 58.0 & $<0.05$ \\
\hline$+\mathrm{Si}$ & 61.4 & 57.0 & $<0.05$ & 56.3 & 62.1 & $<0.05$ \\
\hline$P$ & $<0.05$ & $<0.05$ & & $<0.05$ & $<0.05$ & \\
\hline
\end{tabular}

The factor interaction effects were sliced and means compared by $F$-test. Data showed are from two pooled experiments.

TABLE 7 - Kernel diameter (KD) of rice grains from plants of cultivar Oochikara and lsil mutant grown in hydroponic culture amended with $0(-\mathrm{Si})$ or $2(+\mathrm{Si}) \mathrm{mM}$ of silicon and subjected or not to panicle inoculation with Bipolaris oryzae.

\begin{tabular}{|c|c|c|c|c|c|c|}
\hline \multirow[t]{2}{*}{ Si rates } & \multicolumn{3}{|c|}{ KD (mm) } & \multicolumn{3}{|c|}{ KD (mm) } \\
\hline & Oochikara & lsi1 mutant & $P$ & Inoculated & Non-inoculated & $P$ \\
\hline$-\mathrm{Si}$ & 2.61 & 2.47 & 0.001 & 2.40 & 2.67 & $<0.05$ \\
\hline$+\mathrm{Si}$ & 2.78 & 2.75 & 0.401 & 2.76 & 2.77 & 0.809 \\
\hline$P$ & $<0.05$ & $<0.05$ & & $<0.05$ & $<0.05$ & \\
\hline
\end{tabular}

The factor interaction effects were sliced and means compared by $F$-test. Data showed are from two pooled experiments.

the rice plants may provide a viable alternative to reduce the damage caused by B. oryzae on panicles and, consequently, on the number of grains produced per panicle.

Although there was a significant increase on the number of grains per panicle on the $\mathrm{Si}+$ plants, the weight of 1000 grains and the percentage of filled grains did not improve as much when compared to the Si- plants (Tables 3 and 4). That may be due to the absence of leaf symptoms or to the lower number of grains per panicle in the -Si plants, which resulted in a reduced number of photoassimilate sinks, thus increasing grain weight for the -Si plants. However, in the inoculated panicles of the cv. Oochikara and lsil mutant, especially on plants without $\mathrm{Si}$ which showed the highest BSI values, a reduction of grain weight and of the percentage of filled grains occurred, probably because of a disruption in the translocation of photoassimilates to the developing grain. Husk infection affected grains weight and the percentage of filled grains due to loss of sink function. Prabhu et al. (1980) reported that the variation in grain weight was mainly explained by grain husk infection by $B$. oryzae, with a negative linear relationship between brown spot severity in the grains and the percentage of filled grains. Thus, the lower values for BSI in the grains from panicles from plants supplied with $\mathrm{Si}$, especially of the cv. Oochikara, had less of an impact on grain weight and the percentage of filled grains as compared with the grain obtained from the panicles of the plants without Si.

The increase in $\mathrm{Si}$ concentration was also important for the production of grains with better quality, characterized by yield of both husked and whole kernel, after the milling process (Tables 5 and 6). The yield of whole kernel obtained after grinding and sieving is one of the most important variables related to value in rice marketing (Oliveira et al., 1998). Well-filled rice grains are more resistant to shock and vibration occurring during the harvest and the milling process, resulting in commercial grain of the highest quality (Castro et al., 1999). Mechanical damage to the grains, affecting the yield of intact kernel, occurs from the indirect action of several biotic and abiotic stresses, such as the lack or the excess of rain, insects and diseases (Castro et al., 1999). Diseases, such as brown spot, affect rice quality by causing grain discoloration and affecting grain filling and ripening, therefore accelerating the drying process and resulting in a greater incidence of cracked grains. The functional Lsil gene for cv. Oochikara increased the concentration of $\mathrm{Si}$ in the husks, thus favoring an increase in whole kernel yield and grain diameter by reducing disease severity and transpiration, while keeping high moisture content within the husk that is important for normal grain development (Seo \& Ota, 1982). As husks do not have stomata, the transpiration occurs through the cuticle and the double layer of cuticle-silica beneath the cuticle prevents excessive transpiration reducing it by 30 to $40 \%$ (Yoshida, 1965; Ma \& Takahashi, 2002), allowing a normal and continuous process for grain filling.

In conclusion, the importance of $\mathrm{Si}$ for increasing the production of high quality grains under stressful biotic conditions was demonstrated by growing plants either without Si or using the lsil mutant. Clearly increasing the concentration of $\mathrm{Si}$ in the rice husks may be a strategy to reduce brown spot while achieving better yield and grain quality. The Lsil gene played a pivotal role to increase the whole kernel yield under $B$. oryzae infection.

\section{ACKNOWLEDGMENTS}

L.J. Dallagnol and F.A. Rodrigues were supported by Conselho Nacional de Desenvolvimento Científico e Tecnológico - CNPq. The authors would like to express their appreciation to Dr. A.S. Prabhu for kindly providing 
the isolate of Bipolaris oryzae used in this study and to Prof. G.H. Korndörfer for Si analysis. This work was supported by grants from Coordenação de Aperfeiçoamento de Pessoal de Nível Superior - CAPES, CNPq and Fundação de Amparo à Pesquisa do estado de Minas Gerais - FAPEMIG to Prof. F.A. Rodrigues and by a grant from the Ministry of Agriculture, Forestry and Fisheries of Japan (Genomics for Agricultural Innovation IPG-0006) to Prof. J.F. Ma.

\section{REFERENCES}

Aluko MO (1975) Crop losses caused by the brown leaf spot disease of rice in Nigeria. Plant Disease Reporter 59:609-613.

Ba VV, Sangchote S (2006) Seed borne and transmission of Bipolaris oryzae, the causal pathogen of brown spot of rice. Kasetsart Journal: Natural Science 40:353-360.

Bélanger RR, Guérin V, Cogliati E, Vivancos J, Grégoire C, Labbé C, Belzile F, Menzies JG (2012) Silicon and disease resistance in plants: what is behind the phenomenon? In: Rodrigues FA, Fortunato AA, Resende RS (Eds.) Indução de Resistência em Plantas a Patógenos. Viçosa MG, Brazil. Universidade Federal de Viçosa. pp. 257-276.

Bockhaven JV, De Vleesschauwer D, Höfte M (2012) Towards establishing broad-spectrum disease resistance in plants: silicon leads the way. Journal of Experimental Botany 64:1281-1293.

Castro EM, Vieira NRA, Rabelo RR, Silva SA (1999) Qualidade de grãos de arroz. Santo Antônio de Goiás GO, Brazil. Embrapa Arroz e Feijão.

Dallagnol LJ, Rodrigues FA, Mielli MVB, Ma JF, Datnoff LE (2009) Defective active silicon uptake affects some components of rice resistance to brown spot. Phytopathology 99:116-121.

Dallagnol LJ, Rodrigues FA, DaMatta FM, Mielli MVB, Pereira SC (2011) Deficiency in silicon uptake affects cytological, physiological, and biochemical events in the rice-Bipolaris oryzae interaction. Phytopathology 101:92-104.

Dallagnol LJ, Rodrigues FA, Tanaka FAO, Amorim L, Camargo LEA (2012) Effect of potassium silicate on epidemic components of powdery mildew on melon. Plant Pathology 61:323-330.

Datnoff LE, Raid RN, Snyder GH, Jones DB (1991) Effect of calcium silicate on blast and brown spot intensities and yields of rice. Plant Disease 75:729-732.

Datnoff LE, Snyder GH, Deren CW (1992) Influence of silicon fertilizer grades on blast and brown spot development and on rice yields. Plant Disease 76:1011-1013.

Datnoff LE, Deren CW, Snyder GH (1997) Silicon fertilization for disease management of rice in Florida. Crop Protection 16:525531.

Datnoff LE, Rodrigues FA, Seebold KW (2007) Silicon and plant disease. In: Datnoff LE, Elmer WH, Huber DM (Eds.) Mineral Nutrition and Plant Disease. St. Paul MN, USA. APS Press. pp. 233-246.

Gangopadhyay S, Chatopadhyay SB (1974) Total silica and brown spot disease development of rice under varying levels of nitrogen. Current Science 44:91-94.

Ghareeb H, Bozsó A, Ott PG, Repenning C, Stahl F, Wydra K
(2011) Transcriptome of silicon-induced resistance against Ralstonia solanacearum in the silicon non-accumulator tomato implicates priming effect. Physiological and Molecular Plant Pathology 75:83-89.

Hoagland DR, Arnon DI (1950) The water culture method for growing plant without soil. Circular of California Agricultural Experimental Station 347:1-32.

Houston DF (1972) Rice - Chemistry and Technology. St. Paul MN, USA. American Association of Cereal Chemists.

IRRI (1996) Standard evaluation system for rice. Los Banos Philippines. International Rice Research Institute.

Korndörfer GH, Datnoff LE, Corrêa GF (1999) Influence of silicon on grain discoloration and upland rice grown on four savanna soils from Brazil. Journal of Plant Nutrition 22:93-102.

Korndörfer GH, Pereira HS, Nolla A (2004) Análise de Silício: Solo, Planta e Fertilizante. Uberlândia MG, Brazil. Universidade Federal de Uberlândia.

Ma JF, Takahashi E (2002) Soil, Fertilizer, and Plant Silicon Research in Japan. Amsterdam The Netherlands. Elsevier Science.

Ma JF, Tamai K, Ichii M, Wu GF (2002) A rice mutant defective in Si uptake. Plant Physiology 130:2111-2117.

Ma JF, Tamai K, Yamaji N, Mitani N, Konishi S, Katsuhara M, Ishiguro M, Murata Y, Yano M (2006) A silicon transporter in rice. Nature 430:688-691.

Ma JF, Yamaji N (2008) Functions and transport of silicon in plants. Cellular and Molecular Life Sciences 65:3049-3057.

Maclean JL, Dawe DC, Hardy B, Hettel GP (2002) Rice Almanac. Los Baños Philippines. International Rice Research Institute.

Marchetti MA, Petersen HD (1984) The role of Bipolaris oryzae in floral abortion and kernel discoloration in rice. Plant Disease 68:288-291.

McKinney HH (1923) Influence of soil temperature and moisture on infection of wheat seedlings by Helminthosporium sativum. Journal of Agricultural Research 26:195-218.

Nanda HP, Gangopadhyay S (1984) Role of silicated cells in rice leaf on brown spot disease incidence by Bipolaris oryzae. International Journal of Tropical Plant Diseases 2:89-98.

Oliveira GS, Arf O, Sá ME, Rodrigues RAF (1998) Efeito de espaçamentos e densidades de semeadura sobre o desenvolvimento de cultivares de arroz de sequeiro irrigado por aspersão - II. Componentes do rendimento de engenho. In: VI Reunião Nacional de Pesquisa de Arroz, Resumos... Goiânia GO, Brazil. Embrapa CNPAF. pp.49-52.

Ou SH (1985) Rice Diseases. Kew UK. CAB International Mycological Institute.

Prabhu AS, Lopes AM, Zimmermann FJ (1980) Infecção da folha e do grão de arroz por Helminthosporium oryzae e seus efeitos sobre os componentes de produção. Pesquisa Agropecuária Brasileira 15:183-189.

Seebold KW, Datnoff LE, Correa-Victoria FJ, Kucharek TA, Snyder GH (2000) Effect of silicon rate and host resistance on blast, scald, and yield of upland rice. Plant Disease 84:871-876.

Seo W, Ota Y (1982) Role of the hull in the ripening of the rice plant. Part 5. Water loss in hull and development of rice kernel. 
Japanese Journal of Crop Science 51:529-534.

Soave J, Pizzinatto MA, Usberti Junior JA, Camargo OBA, Villela OV (1984) Selection of rice cultivars resistant to some pathogens using seed health testing. Pesquisa Agropecuária Brasileira 19:449-453.

Tamai K, Ma JF (2008) Reexamination of silicon effects on rice growth and production under field conditions using a low silicon mutant. Plant and Soil 307:21-27.

Yamaji N, Ma JF (2009) A transporter at the node responsible for intervascular transfer of silicon in rice. Plant Cell 21:2878-2883.

Yoshida S (1965) Chemical aspects of silicon in physiology of the rice plant. Bulletin of the National Institute of Agricultural Science 15:1-58.

TPP 2013-0081

Submitted: 17 May 2013

Revisions requested: 10 September 2013 Accepted: 16 September 2013

Section Editor: Adalberto C. Café Filho 